\title{
DNA Fingerprinting - An Asset to Forensic Dentistry
}

\author{
Aditi Sharma*1, Akshat Sachdeva ${ }^{1}$, Sumit Bhateja ${ }^{1}$ and Geetika Arora ${ }^{2}$ \\ ${ }^{1}$ Reader, Department of Oral Medicine and Radiology, Manav Rachna Dental College, India \\ ${ }^{2}$ Reader Department of Public Health Dentistry, Inderprastha Dental College, India
}

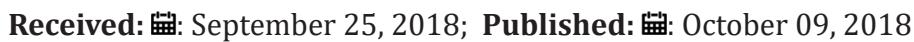

*Corresponding author: Aditi Sharma, Dental Surgeon, Manav Rachna Dental College, Haryana, India

\begin{abstract}
The recent advances in molecular biology have revolutionized all aspects of dentistry. DNA, the language of life yields information beyond our imagination, both in health or disease. To uncover all the mysteries linked with the oral cavity and its manifestations during diseased conditions, DNA fingerprinting is the most appropriate tool. It is being increasingly used in analyzing various scenarios related to forensic science. The use of DNA profile test in forensic dentistry offers a new perspective in human identification. DNA is responsible for storing all the genetic material and is unique to each individual. The currently available DNA tests have high reliability and are accepted as legal proofs in courts. This article gives an overview of the evolution of DNA technology in the last few years, highlighting its importance in cases of forensic investigation.
\end{abstract}

Keywords: DNA Fingerprinting; Forensic Dentistry; Teeth

\section{Introduction}

DNA fingerprinting (also called DNA profiling, or DNA typing) invented in 1984 by Professor Sir Alec Jeffreys, refers to the approach of determining an individual's DNA characteristics [1]. Criminal identification which may include differentiation of one or more individuals' profiles using DNA found at the site of crime so as to assess the likelihood of their involvement in the crime, has become simplified in today's modern era just because of DNA fingerprinting [2]. It also finds its application in parentage testing, [3] to establish immigration eligibility [4], and in genealogical and medical research. Various studies on animal and plant populations in the field of zoology, botany and agriculture have been performed through DNA fingerprinting [5]. The tooth has proven most valuable source to extract DNA in the field of dentistry since it is a bolted box preserving DNA from extreme environmental conditions. This has led to the investigation of various human tissues as potential source of genetic evidentiary material. In today's transforming era, teeth have proven to be a potent source of DNA studies as this hard tissue encloses the pulp from where DNA can be withdrawn [6]. Moreover, when morphologically evaluated, even a single tooth can provide valuable information regarding the individual to whom the tooth belongs [7].

\section{Principle for DNA Fingerprinting}

The gene coding for a particular protein contains 95\% junk or noncoding DNA and only $2-5 \%$ of coding DNA. This junk DNA may be present as a single copy of spacer DNA or as multiple copies called repetitive DNA. The repetitive sequence exists as long or STRs. The variation in the mini satellite pattern that is detected by a probe along with stable inheritance forms the basis for DNA fingerprinting [8].
DNA-types:

a) Genomic DNA - Teeth provide a good source of genomic DNA [9]. They are within the nucleus of the cell.

b) Mitochondrial DNA - Used when DNA sample obtained is insufficient or degraded [10].

Stages in DNA extraction:

a) Cell membrane rupture

b) Denaturation of proteins using chelating agents and inactivation using proteinases

c) DNA extraction. Most commonly DNA is extracted by organic method (phenol) or by Chelex 100 (Bio Rad Laboratories, Inc), FTA paper (WhatmanInc, Clifton, NJ) or isopropyl alcohol [11].

\section{DNA Fingerprinting Process}

DNA profiling or fingerprinting reveals the genetic makeup of a person. Teeth provide an excellent source of DNA as they remain virtually unaffected by environmental assaults. Proper DNA isolation and quantification are needed to perform a successful analysis. The various ways of running a DNA fingerprint are as follows:

\section{Restriction Fragment Length Polymorphism Method}

After the evidence is collected from the crime scene, DNA is isolated. Using a special enzyme (restriction endonuclease) that acts as molecular scissors, DNA is cut into fragments at sites that are not found within the tandem repeat sequence. The chopped 
fragments have VNTR of varying lengths. [12] Gel electrophoresis is done to separate the cut fragments based on their size. A Southern Blot (transferring the fragments to a nitrocellulose filter) is then performed, and a radioactive probe is used to analyze the DNA. Restriction fragment length polymorphism, by defining a specific pattern to VNTR via detecting the repetitive sequences, form the DNA fingerprint of an individual. Restriction fragment length polymorphism (RFLP) requires large quantities of DNA and requires long waiting time to obtain results [13].

\section{Polymerase Chain Reaction (PCR)}

The available DNA is amplified to carry out the analysis using a special enzyme and DNA primers, which are explicit for human DNA, and the results remain unaffected even if bacterial DNA is present in the sample. The principle of PCR is the ability of DNA to replicate itself. When the strands of DNA unwind during duplication, the primer is employed to amplify specific segments. In a couple of hours, DNA is amplified to about 109 times the original amount and the reaction runs through 30 cycles [14]. Amplicons are the products of amplification, which are then detached by electrophoresis. PCR is used for evaluating VNTR, particularly the frequencies of STR loci. To determine the quantity of male or female DNA in a mixed sample, as in sexual assault cases, real-time PCR or quantitative PCR was developed.

\section{Short Tandem Repeat (Str) Typing}

It is a frequently and routinely used marker in forensics. STRs have a high power of individual discernment because of their high standards of polymorphic informative content. The non overlapping size of the alleles from different contributors serves to distinguish them. Currently, they are detected by fluorescent detection methods using capillary or gel electrophoresis and even by ABI gel-based DNA sequencers while earlier works on detection involved silver-stained polyacrylamide gels. Used in paternity testing as each individual has some STRs inherited from father and some from the mother [15] They are hyper-variable regions that show repetitions of fragments having 2-7 base pairs [16]. It helps in identifying victims of mass calamities from even old remains [17]. To serve as the standard for the combined DNA index systems (CODIS), federal bureau of investigation has chosen 13 definite STR loci [18] which are together referred to as CODIS markers and the sex identifying amelogenin marker. Various commercial kits are available that amplify the 13 core loci and amelogenin.

\section{Analysis of Mitochondrial DNA (mtDNA)}

In instances where analysis of nuclear DNA cannot be done, Mt DNA analysis can be used for ancient tissues like bone, hair and teeth as stated by Silva and Passos in 2002 [19]. High molecular weight mtDNA are obtained from teeth, especially in degraded remains [20]. Every child has the same mtDNA as its mother because mitochondrion of the embryo is from the mother's egg while genomic DNA is from father's sperm. It is thus a valuable tool in identifying missing persons by comparing mtDNA of unidentified remains with that of a possible maternal relative [21]. As the technique involves direct sequencing of nitrogenous bases, therefore it is expensive. Moreover, it provides limited information due to the involvement of familial relationship which can be traced from the female member of the respective family.

\section{Analysis of Y Chromosome}

It involves targeting of the polymorphic regions of the $Y$ chromosome (Y - STR) using primers. As Y chromosome is passed to the son from his father, analysis of markers on the chromosome helps in sketching relationships among males [22].

\section{Single Nucleotide Polymorphism}

The alterations in nucleotide sequence results in variation which are known as single nucleotide polymorphism. E.g.: An SNP may change the nucleotide sequence AAGGCTAA to ATGGCTAA [23]. Provides valuable information on descent, sex, evolution and is highly automated [24]. Their advantage is that they can identify highly degraded DNA fragments.

\section{Applications of DNA Fingerprinting}

[25] Branches like paleontology, archaeology, various fields of biology, and medical diagnostics involve application of techniques used in DNA fingerprinting. In criminal investigations, the suspect's blood or other body material is matched to that of the evidence from the crime scene using DNA fingerprinting. Paternal disputes can also be resolved using this technique. The worldwide acceptance of the technique is undoubtedly an asset to this planet and has been used to acquit or free persons convicted of crimes. When appropriately performed, DNA fingerprinting is one of the most reliable forensic tools, but a wider sample of human DNA is required by the scientist to ensure that the segments being analyzed are highly volatile for the human race.

\section{DNA \& Forensic Dentistry}

DNA can be successfully extracted from dentin and pulp [26]. Abundant quality DNA can be extracted from a tooth which is an important advantage in DNA analysis [27]. DNA is preserved in the teeth and bones for a very long period and thus is a valuable source of information. Various methods have been reported regarding the extraction of DNA from the tooth which includes sectioning of teeth horizontally at the cemento- enamel junction or vertically up to root tip, scraping and aspiration. Other methods include crushing of the teeth or cryogenic grinding or conventional access cavity preparation and retrieval of dental pulp. The advantages of access cavity preparation technique are its simplicity, relatively low cost and preservation of the tooth integrity which can be considered in forensic investigations. [28] Environmental factors leading to the degradation of DNA include time, temperature, humidity (facilitating the growth of microorganisms), light (both sunlight and UV light) and exposure to various chemical substances. DNA extraction process is composed of 3 different stages: cell rupture or lysis (which allows use of several techniques for effective rupture of the cell membranes), protein denaturation and inactivation (by chelating agents and proteinases in order to inactive elements, such as proteins), and finally DNA extraction itself [29].

Majorly, the Organic Method DNA extraction technique is most often employed in Forensic Dentistry (composed of phenol- 
chloroform, used for high molecular weight DNA and is laborious, time consuming, with a higher risk of errors, given the use of multiple tubes and can only be done if abundance of sample is available); Chelex 100 (the fastest with the lowest risk of contamination, yet very expensive); FTA Paper (composed of absorbent cellulose paper with chemical substances, which speed up its use); and isopropyl alcohol (containing ammonium and isopropanol, which is less expensive and also an alternative to the organic method) [30]. Application of DNA fingerprinting in forensic odontology include instances were DNA is not available in any other part of the body as in case of major disasters like plane crash, charred bodies, decomposed bodies and building collapse [31]. A very interesting case was presented by Sweet and Sweet (1995) in which a victim was incinerated and her body was completely carbonized and DNA extraction by usual method was not possible. However, her body was identified after an unerupted third molar enabled extraction of DNA [32].

Human saliva has been shown to be an excellent source of high molecular weight DNA. Saliva recovered from material at crime scenes (i.e. clothing, cigarette butts, postage stamps, envelope stamps) has been completely isolated, analyzed and compared to reference sources obtained from suspects [33]. Saliva is normally deposited on human skin during biting, sucking, licking and kissing, so the potential use of the DNA present in saliva stains on skin shows any role of the suspect in causing a given bite mark. Swabbing of the skin to collect saliva for the collection of bite mark evidence is advocated as a part of the standard operating procedure by the American Board of Forensic Odontology (ABFO), 1995. These swabs can be tested for amylase, a component of saliva. A positive test result confirms the presence of saliva and that the observed injury is in fact a bite mark [33].

\section{Conclusion}

The arrival of DNA finger printing has revolutionized the concept of identification. DNA has been isolated and characterized from the dental pulp and saliva. For the purpose of uncovering the recordings and investigating the injury and abuse cases, every dentist must not only have the knowledge, but should also be aware of the importance of forensic dentistry and its applications. As forensic odontologists' have a major role to play in identification of victims in mass disasters, a good quality of dental records makes the identification process easier. Teeth are unique and resistant to destruction and their records when well-maintained have a major impact in identification process. Using the DNA analysis' methods, DNA testing can be a powerful method of human identification.

\section{References}

1. Murphy, Erin (2017) Forensic DNA Typing. Annual Review of Criminology.

2. Petersen K (2012) Handbook of Surveillance Technologies. ( $3^{\text {rd }}$ Edn.). Boca p. 815.

3. (2011) DNA pioneer's 'eureka' moment BBC.

4. Chambers, Geoffrey K, Curtis, Caitlin, Millar, et al. (2014) DNA fingerprinting in zoology: past, present, future. Investigative Genetics 5: 3 .
5. Sweet D (2001) Why a dentist for identification? Dent Clin North Am 45: 237-251.

6. Sweet D, Hildebrand D, Phillips D (1999) Identification of skeleton using DNA from teeth and a PAP smear. J Forensic Sci 44: 630-633.

7. Pareek CS, Smoczynski R, Tretyn A (2011) Sequencing technologies and genome sequencing. J Appl Genet 52: 413-435.

8. Alonso A, Martin P, Albarrán C, Garcia P, Fernandez de Simon L, et al. (2005) Challenges of DNA profiling in mass disaster investigations. Croat Med J 46: 540-548.

9. Sweet DJ, Sweet CH (1995) DNA analysis of dental pulp to link incinerated remains of homicide victim to crime scene. J Forensic Sci 40: 310-314.

10. Datta P, Sood S, Rastogi P, Bhargava K, Bhargava D, et al. (2012) DNA profiling in forensic dentistry. J Indian Acad Forensic Med 34:156-158.

11. Vogel F, Motulsky AG, Motta PA (2000) Rio de Janeiro: Guanabara Koogan Human genetics: Problems and approach.

12. Girish K, Rahman FS, Tippu SR (2010) Dental DNA fingerprinting in identification of human remains. J Forensic Dent Sci 2: 63-68.

13. Zehner R, Zimmermann S, Mebs D (1998) RFLP and sequence analysis of the cytochrome $b$ gene of selected animals and man: Methodology and forensic application. Int J Legal Med 111: 323-327.

14. Brannon RB, Kessler HP (1999) Problems in mass-disaster dental identification: A retrospective review. J Forensic Sci 44: 123-127.

15. Butler JM (2006) Genetics and genomics of core short tandem repeat loci used in human identity testing. J Forensic Sci 51: 253-265.

16. Boljuncic J (2007) DNA analysis of early mediaeval individuals from the Zvonimirovo burial site in Northern Croatia: Investigation of kinship relationships by using multiplex system amplification for short tandem repeat loci. Croat Med J 48: 536-546.

17. Chakraborty R, Stivers DN, Su B, Zhong Y, Budowle B (1999) The utility of short tandem repeat loci beyond human identification: Implications for development of new DNA typing systems. Electrophoresis 20: 16821696.

18. Silva LA, Passos NS (2002) DNA forense: Collection of biological samples at crime scenes to study DNA.

19. Koyama H, Iwasa M, Ohtani S, Ohira H, Tsuchimochi T, et al. (2002) Personal identification from human remains by mitochondrial DNA sequencing. Am J Forensic Med Pathol 23: 272-276.

20. Budowle B, DiZinno JA, Wilson MR (2011) Interpretation Guidelines for mitochondrial DNA sequencing.

21. Zhong H, Shi H, Qi XB, Xiao CJ, Jin L, et al. (2010) Global distribution of Y-chromosome haplogroup $\mathrm{C}$ reveals the prehistoric migration routes of African exodus and early settlement in East Asia. J Hum Genet 55: 428435.

22. (2011) SNP Fact Sheet. Human genome project. U.S. Department of Energy genome Program's biological and environmental research information system (BERIS).

23. Kwok PY, Chen X (2003) Detection of single nucleotide polymorphisms. Curr Issues Mol Biol 5: 43-60.

24. Shiroma CY, Fielding CG, Lewis JA (2004) A minimally destructive technique for sampling dentin powder for mitochondrial DNA testing. J Forensic Sci 49: 791-795.

25. Corte-Real A, Andrade L, Anjos MJ (2006) The DNA extraction from the pulp dentine complex of both with and without carious. Int Congress Ser 1288: 710-712.

26. Pinchi V, Torricelli F, Nutini AL (2011) Techniques of dental DNA extraction: some operative experiences. Forensic SciInt 204: 111-114.

27. Butler J M (2005) Forensic DNA Typing: biology, technology and genetics of STR markers. San Diego: Academic Press. 
28. Sweet D, DiZinno JA (1996) Personal identification through dental evidence-tooth fragments to DNA. J Calif. Dental Assoc 24: 35-42.

29. Sweet D (2001) Why a dentist for identification? Dent Clin North Am 45: $237-251$.

30. Sweet DJ, Sweet CH (1995) DNA analysis of dental pulp to link incinerated remains of homicide victim to crime scene. J Forensic Sci 40: 310-314.

\section{ISSN: 2574-1241}

DOI: 10.26717/BJSTR.2018.09.001855

Aditi Sharma. Biomed J Sci \& Tech Res

(c) (9) This work is licensed under Creative

Submission Link: https://biomedres.us/submit-manuscript.php
31. Sunit Kumar J (2012) Tooth Pulp: A Foundation for DNA Analysis. J Forensic Res 3: e111.

32. https://en.wikipedia.org/wiki/DNA_profiling\#cite_note-2

33. https://www.infoplease.com/encyclopedia/science-and-technology/ biology-and-genetics/genetics-and-genetic-engineering/dnafingerprinting/applications

$\begin{array}{ll}\text { BIOMEDICAL } & \begin{array}{l}\text { Assets of Publishing with us } \\ \text { RESEARCHES }\end{array} \\ \text { - Global archiving of articles }\end{array}$

